\title{
DETERMINAÇÃO DO CAMPO TÉRMICO A PARTIR DA CLASSIFICAÇÃO DA PAISAGEM DOS AMBIENTES CLIMÁTICOS INTRAURBANOS
}

\author{
CAMILA AMARO DE SOUZA, Dra. | UNIDERP \\ ANTÔNIO CONCEIÇÃO PARANHOS FILHO, Dr. | UNIDERP \\ ELIANE GUARALDO, Dra. | UNIDERP
}

\section{RESUMO}

As cidades representam um modo de alteração intensa do cenário natural, pois sua implantação altera a morfologia do suporte físico devido ao uso e ocupação do solo e modifica os aspectos ambientais e atmosféricos (MONTEIRO, 2003). Cerca de 3\% do território terrestre livre de gelo corresponde a áreas urbanizadas e, simultaneamente, concentra mais de $50 \%$ da população do planeta e grande parcela das atividades humanas (GERALD, 2007).

O conceito de paisagem de Sauer (1925 apud CORRÊA, 1998, p.13) é definido como sendo algo complexo e que envolve todos os elementos, sejam eles naturais e sociais. Ainda decompõe paisagem em dois elementos: o "sítio", que significa a soma dos recursos naturais; e a sua expressão cultural, ou a marca da ação do homem sobre uma área. A partir da década de 1980 avivaram-se os diferentes estudos pertinentes à paisagem, numa abordagem sistêmica e conectada aos componentes ambientais.

A história dos habitats urbanos não é apenas de adaptação passiva ao clima regional, mas de transformação ativa para produzir microclimas radicalmente diferentes do terreno circundante. $O$ design da cidade é o tipo mais antigo de mudança climática antropogênica (EGLI, 1951) apud (HEBBERT; JANKOVIC, 2013, p. 1334, tradução nossa).

Dado o rápido aumento da urbanização global, é preciso entender como o processo de expansão urbana afeta o microclima, o clima local e regional.

A perspectiva da climatologia urbana traz à tona um conjunto diferente de fatores climáticos como, por exemplo, o movimento do ar, talvez a mais importante variável microclimática que afeta o conforto térmico humano, ocorre em todas as cidades a cada hora do dia e da noite e é diretamente afetado pelo formato dos edifícios e pela morfologia urbana (HEBBERT; JANKOVIC, 2013).

A pesquisa sobre o aumento dos efeitos das mudanças climáticas peloaquecimento urbanolocal (caracterizada por ilhas de calor urbanas) permanece incipiente (EMMANUEL; LOCONSOLE, 2015, p.71, tradução nossa).

Uma das principais dificuldades em desvendar o aquecimento urbano são as técnicas computacionais e análises paramétricas associadas à representação de áreas urbanas em modelos climáticos (GRAWE et al., 2013; JIN; DICKINSON; ZHANG, 2005). Além disso, são utilizadas com frequência técnicas de cálculos estatísticos para modelos climáticos globais sem modelar as próprias áreas urbanas (LEMONSU et al., 2013).

Embora a situação continue a evoluir positivamente (HEBBERT; JANKOVIC, 2013), muito ainda precisa ser feito para (a) melhorar o efeito de ilha de calor urbana (ICU) e (b) usar as formas de mitigação de ICU como parte da adaptação às mudanças climáticas locais.

A antropização dos ambientes altera os balanços hídricos e energéticos nas camadas atmosféricas próximas à superfície (devido à supressão de vegetação), diminuindo a evapotranspiração e aumentando o escoamento superficial de água (OKE, 1987, p.262).

O uso de vegetação e implementação de infraestrutura verde, vêm sendo incentivados para auxiliar na amenização do impacto que as cidades promovem (Figura 1).

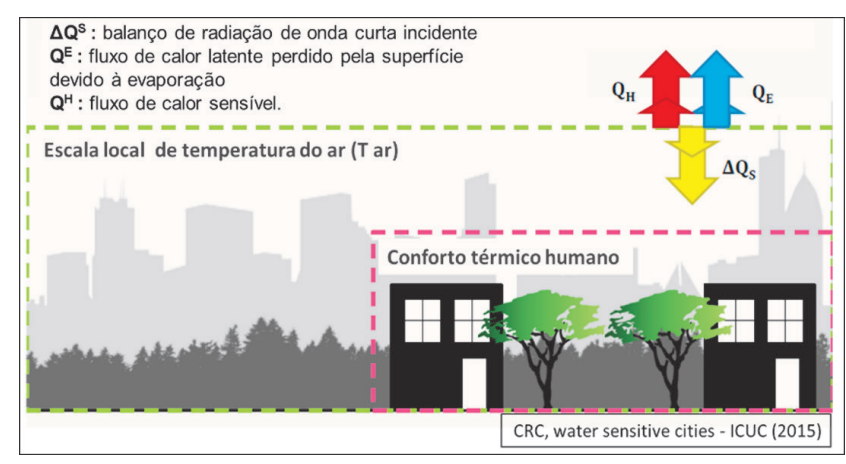

Figura 1 - Esquema de implementação de vegetação, proporcionando conforto térmico. Reduz a temperatura do ar (Tar), aumenta o fluxo de calor latente perdido pela superfície devido à evaporação $(\mathrm{QE})$ e diminui o fluxo de calor sensível $(\mathrm{QH})$ e 0 balanço de radiação de onda curta incidente $(\triangle \mathrm{QS})$. Fonte: Adaptado de CRC, water sensitive cities - ICUC (2015). 
São relevantes no que tange as seguintes variáveis: temperatura do ar (Tar) e umidade relativa do ar (UR); ventilação, poluição atmosférica, da água e do solo; drenagem, estabilidade dos solos e biodiversidade, e ainda está diretamente ligado à saúde e ao bem-estar da população, ou seja, relaciona-se diretamente com o conforto ambiental (GIVONI, 1998; HOUGH, 1998; LOMBARDO et al., 2012; NOWAK, 1994; ULRICH et al., 1991; WONG; CHEN, 2009).

Na escala microclimática (pensando no conforto térmico humano) os efeitos da vegetação dependem de diversos fatores como: a densidade das folhas, os tipos de folhas e galhos (e.g. folhas pilosas ou lisas, grandes ou pequenas etc.), o porte da vegetação, a disponibilidade de água no solo e sua localização. Esses fatores variam conforme as interações entre: o solo, a vegetação e a camada atmosférica; a faixa etária, tipo de espécie e a estação do ano. Estes, por sua vez, interagem de forma complexa com a Tar, estando ligados prioritariamente a dois mecanismos: o sombreamento e a evapotranspiração (ADAMS; SMITH, 2014; FERREIRA, 2012; OKE et al., 2017; WONG; CHEN, 2009).

Souza (2016) demonstrou a influência de parques urbanos de recreação nas temperaturas do ar das áreas urbanas, verificou que em Campo Grande, regiões de parques mais arborizados como o Parque das Nações Indígenas e presença de corpo d'água a temperatura do ar apresenta médias mais amenas do que em parques com vegetação rasteira como o Parque Ayrton Senna.

De acordo com Coutts (2015), outra vantagem da vegetação arbórea em relação à arbustiva e herbácea é que suas raízes conseguem acessar água em camadas mais profundas do solo. Isso contribui para a maior magnitude do processo de evapotranspiração mesmo em ambiente com baixa umidade relativa do ar e de baixos índices de precipitação, por exemplo.

Esse estudo tem como objetivo em seu Capítulo 1 analisar o sistema de classificação da paisagem para identificação de ilhas de calor urbanas Local Climate Zones (LCZ) (STEWART, 2011a; STEWART e OKE, 2012), como base para o Capítulo 2, que demonstra a identificação das classes climáticas locais existentes na cidade de Campo Grande a partir do uso de imagens de satélite e software SIG de livre acesso. No Capítulo 3 foi realizada a correlação das possíveis LCZs identificadas na cidade com dados de temperatura e umidade relativa do ar coletados, e, no Capítulo 4, foi identificado o campo térmico da cidade a partir de dados climáticos SWERA, cálculos estatísticos com software CLIMATE CONSULTANT 6.0 e elaboração de diretrizes construtivas bioclimáticas adequadas para as diferentes zonas climáticas locais identificadas na cidade e no entorno rural.
As hipóteses que nortearam o trabalho foram as de que áreas com a presença de vegetação arbórea densa e esparsa (LCZ A e B) apresentam menor temperatura do ar ao longo das diferentes estações do ano e que a eliminação ou diminuição de áreas verdes ocasiona aumento de temperatura. Os resultados corroboram que as áreas mais urbanizadas (principalmente as LCZ 2, 3 e 4) apresentam temperatura diurna e noturna superior $\left(+4^{\circ} \mathrm{C}\right)$ às áreas menos urbanizadas. As zonas consideradas urbanizadas nesta pesquisa são heterogêneas, sendo as regiões com maiores índices de vegetação e/ou edifícios mais altos (cânions urbanos) apresentam temperatura inferior a outras tipologias urbanas no período diurno e áreas com edifícios altos e índices de vegetação baixos apresentam temperatura noturna mais elevada, característica compatível com o padrão de ilha de calor urbana, as quais foram registradas com magnitude considerada alta $\left(+5,1^{\circ} \mathrm{C}\right)$.

Foram alcançados dados relevantes sobre as diferentes características das superfícies do solo da área urbana de Campo Grande, Mato Grosso do Sul, que foram processados para elaboração de fichas técnicas e mapas. A interpretação dos dados vai além da área temática, abrangendo o aspecto social, entendendo que o fenômeno ilha de calor repercute não apenas no território em si, como também na maneira desigual de distribuição de áreas verdes, estratégias de planejamento em loteamentos urbanos e o modo de apropriação dos espaços públicos e privados.

A intenção da pesquisa foi propor um conjunto de diretrizes de conforto ambiental inédito para futuras revisões de zoneamento e uso e ocupação do solo na cidade previstos em planos diretores municipais e legislações específicas, e planejamento e gestão urbana e ambiental. A metodologia aplicada nessa tese serve de inspiração para análise de outras cidades de porte médio e outras situações na região centro-oeste. 